\title{
Erratum to: Development and application of gene-based markers for the major rice QTL Phosphorus uptake 1
}

\author{
Joong Hyoun Chin · Xiaochun Lu • Stephan M. Haefele • \\ Rico Gamuyao • Abdelbagi Ismail • Matthias Wissuwa • \\ Sigrid Heuer
}

Published online: 17 February 2010

(C) Springer-Verlag 2010

\section{Erratum to: Theor Appl Genet}

DOI 10.1007/s00122-009-1235-7

Unfortunately, an error occurred in Fig. 6 of the original paper. The corrected figure is given in the following page.

The online version of the original article can be found under doi:10.1007/s00122-009-1235-7.

J. H. Chin · S. M. Haefele · R. Gamuyao - S. Heuer $(\bowtie)$ International Rice Research Institute (IRRI), Plant Breeding, Genetics, and Biotechnology Division (PBGB),

DAPO Box 7777, Metro Manila, Philippines

e-mail: s.heuer@cgiar.org

Present Address:

$\mathrm{X}$. Lu

College of Life Science, Zhejiang University,

Zeijang Campus, 29, 310058 Hangzhou, China

A. Ismail

International Rice Research Institute (IRRI),

Crop and Environmental Sciences Division (CESD),

DAPO Box 7777, Metro Manila, Philippines

M. Wissuwa

Japan International Research Center for Agricultural Sciences

(JIRCAS), 1-1 Ohwashi, Tsukuba, Ibaraki 305-8686, Japan 


\section{(a)}

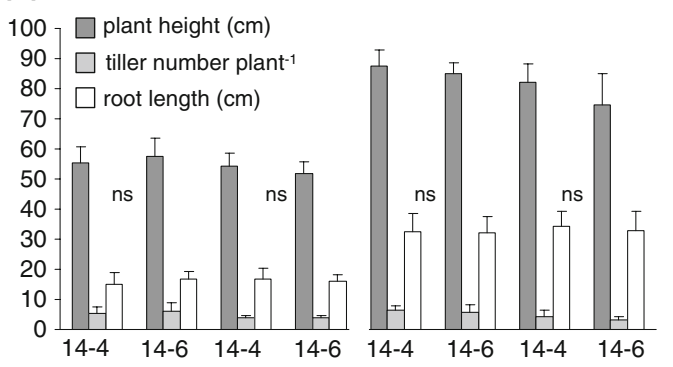

(b)

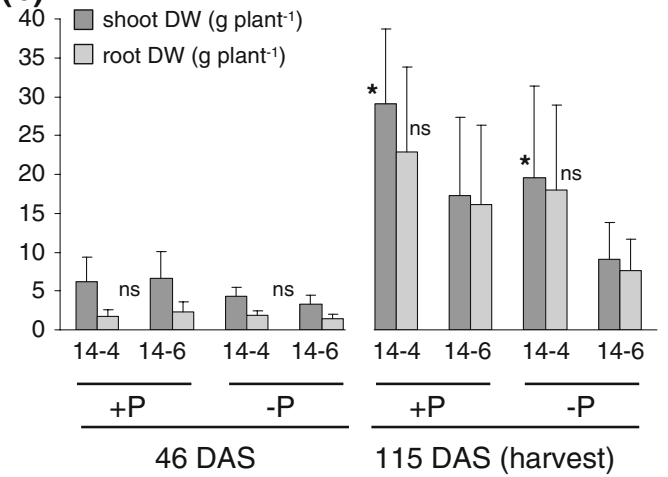

(c)

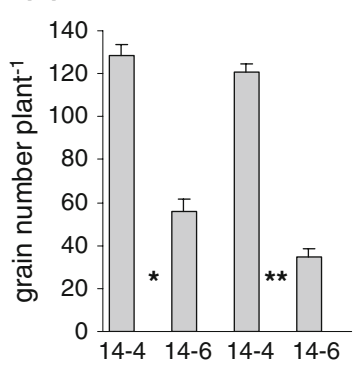

(d)

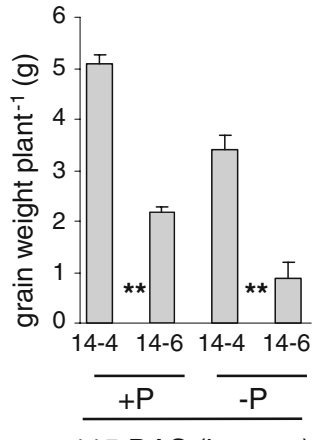

(e)

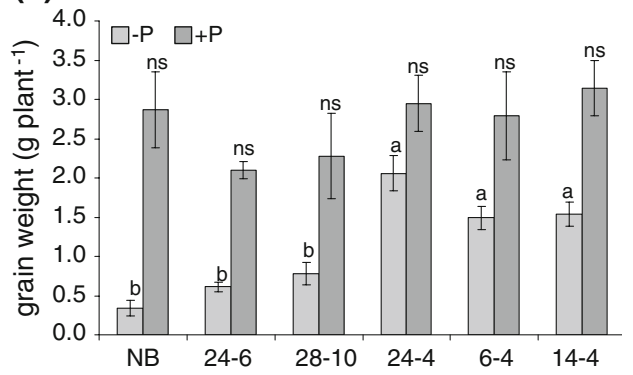

(f)

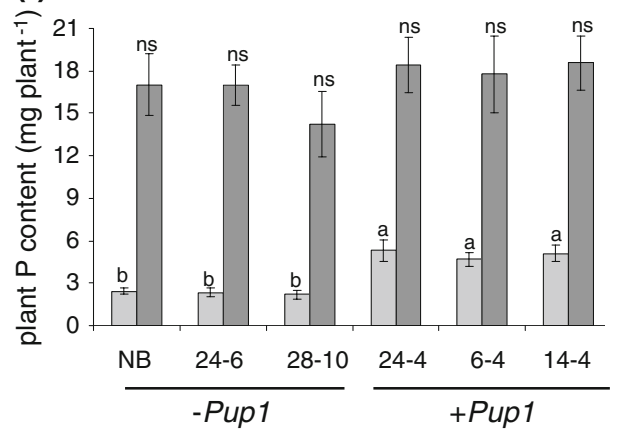

Fig. 6 Pupl phenotype in P-deficient soil. The contrasting Pupl sister lines NIL14-4 (+Pup1) and NIL14-6 (-Pup1) were grown in $\mathrm{P}$-deficient Philippine soil $(-\mathrm{P})$ without and with $\mathrm{P}$-fertilizer $(+\mathrm{P})$ application under well-watered but non-flooded (aerobic) conditions. Plant height, tiller number, and root length (a) as well as shoot and root dry weight plant $^{-1}$ (b) were measured at 46 and 115 days (harvest) when grain number plant ${ }^{-1}$ (c) and grain weight plant ${ }^{-1}$ (d) were determined. In an independent experiment Nipponbare (NB) and
NILs with contrasting Pupl haplotypes (+Pup1: NIL6-4, NIL14-4, NIL24-4; -Pup1: NIL14-6, NIL24-6; Heuer et al. 2009) were grown in P-deficient Japanese soil with $(+\mathrm{P})$ and without $(-\mathrm{P})$ P-fertilizer. Grain weight (e) and plant $\mathrm{P}$ content (f) was determined at maturity. Error bars indicate standard deviations of means; significance levels: $n s$ non significant, *Significant at $p<0.05, * *$ Significant at $p<0.01$. Within $\mathrm{P}$ treatments, different letters signify significant differences according to Tukey's HSD test at $p<0.05$ 